\title{
LA CONDICIÓN DE POBREZA COMO CATEGORÍA SOSPECHOSA DE DISCRIMINACIÓN EN AMÉRICA LATINA
}

Poverty as a suspect classification in Latin America

\author{
MARCOS ANTONIO VELA ÁVALOS \\ Sala de lo Constitucional de la Corte Suprema \\ de Justicia de El Salvador \\ marcos.vela@oj.gob.sv \\ marcos_vela28@hotmail.com
}

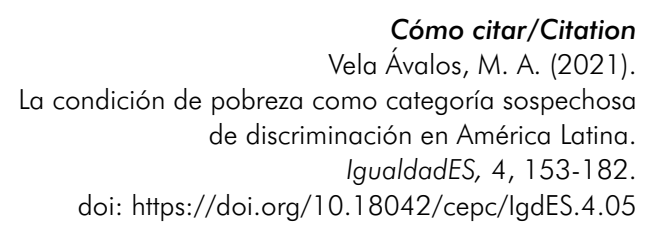

(Recepción: 01/07/2020; aceptación tras revisión: 19/04/2021; publicación: 30/06/2021)

\section{Resumen}

Este trabajo pretende determinar las razones por las que la pobreza se puede considerar como una categoría sospechosa de discriminación a la luz de la Convención Americana sobre Derechos Humanos y de las constituciones de los países de América Latina, que tienen un punto en común al reconocer el principio de igualdad, norma regulativa de la que deriva la prohibición de discriminación. El punto de partida que revela la importancia práctica del tema es el intento por definir qué es la pobreza e informar el estado de cosas existente en la región en relación con la materia. Además, en la parte final de la investigación se exponen las consecuencias inmediatas que tendría esta categorización de la pobreza para los Estados de Latinoamérica, algo relevante en la situación por la COVID-19.

\section{Palabras clave}

Discriminación; pobreza; igualdad; América Latina; COVID-19. 


\section{Abstract}

This work aims to determine the reasons why poverty can be considered as a suspect classification in the American Convention on Human Rights and the constitutions of the states of Latin America, which have a point in common when recognizing equality as a principle, norm from which the prohibition of discrimination derives. The starting point that reveals the practical importance of the subject is the attempt to define what poverty is and to inform the current situation in the region in relation to the matter. Furthermore, in the final part of the research, the immediate consequences that this categorization of poverty would have in Latin America are exposed, which is relevant in the context of COVID-19.

\section{Keywords}

Discrimination; poverty; equality; Latin America; COVID-19. 


\section{SUMARIO}

I. INTRODUCCIÓN. II. POBREZA EN LATINOAMÉRICA: 1. Sobre el concepto de pobreza. 2. El estado de cosas en América Latina. III. CONDICIÓN DE POBREZA COMO CATEGORÍA SOSPECHOSA DE DISCRIMINACIÓN A LA LUZ DE LA CONVENCIÓN AMERICANA SOBRE DERECHOS HUMANOS: 1. Dos conceptos básicos. 2. Condición de pobreza como categoría sospechosa de discriminación en la Convención Americana sobre Derechos Humanos. IV. EL PRINCIPIO DE IGUALDAD EN EL DERECHO INTERNO LATINOAMERICANO Y LA PROHIBICIÓN DE APOROFOBIA: 1. El principio de igualdad y la prohibición de discriminación en las constituciones de América Latina. 2. El principio de igualdad como norma regulativa: la prohibición de discriminación por condición de pobreza (aporofobia) en el Derecho interno latinoamericano. V. CONSECUENCIAS INMEDIATAS DE CONSIDERAR A LA POBREZA COMO CATEGORÍA SOSPECHOSA DE DISCRIMINACIÓN. VI. CONCLUSIONES. BIBLIOGRAFIA.

\section{INTRODUCCIÓN'}

Los estudios doctrinarios e informes institucionales contemporáneos se ocupan profusamente de la cuestión de la pobreza. Para cualquiera que esté interesado en la materia, bastaría con echarles una mirada rápida para advertir dos asuntos sumamente relevantes. El primero es que a pesar de que intuitivamente conceptualizamos a la pobreza como privaciones económicas o bajos ingresos, las opiniones autorizadas sobre el tema nos indican que hay más de un concepto posible (Ramírez Cleves, 2009: 11-14; Greve, 2020:

1 En esta introducción se aclara que las abreviaturas que se utilizarán en este artículo son las que siguen: a) $\mathrm{CADH}=$ Convención Americana sobre Derechos Humanos; b) CEPAL = Comisión Económica para América Latina y el Caribe; c) $\mathrm{CIDH}=$ Comisión Interamericana de Derechos Humanos; d) Corte $\mathrm{IDH}=$ Corte Interamericana de Derechos Humanos; y e) FMI = Fondo Monetario Internacional. También se emplearán las de uso común en las investigaciones jurídicas, tales como art. (artículo), Cn. (Constitución), entre otras. 
21-22; Smeeding, 2016: 21-23)², por lo que la asunción de alguno de esos conceptos debería estar precedida de un análisis crítico que lo muestre como el más adecuado para el contexto en que será empleado. Lo segundo es que las instituciones y órganos nacionales e internacionales han ido ocupándose cada vez más de este problema y de sus posibles soluciones. Pueden citarse como ejemplo a la CIDH (2017), la Organización de las Naciones Unidas (2015: 1), CEPAL (2020d), el FMI y el Banco Mundial (Ahmed y Bredenkamp, 2000: 10-13).

Si se parte de un enfoque monetario de la cuestión, el panorama actual y de futuro inmediato es poco alentador para América Latina. Según los índices recientes, en el 2018 un 30,1\% de latinoamericanos se encontraba por debajo de la línea de pobreza (CEPAL, 2019: 96), y se proyecta que la tasa aumente en un 4,4\% (CEPAL, 2020d: 15-16). A estos datos se adicionan muchos otros que se mencionarán a lo largo de este texto, los cuales apuntan en la misma dirección: existe un problema social profundo y una desigualdad estructural que necesitan de atención interdisciplinaria para ser solucionados. Pero, a pesar de todo esto y de que no se trata de un problema reciente - no ha nacido en América Latina hace poco-, el derecho ha guardado silencio y pareciera mirar a otro lado, pues hay muy poco abordaje jurídico sobre la condición de pobreza por parte de la doctrina latinoamericana ${ }^{3}$.

La necesidad de que existan estudios jurídicos sobre la pobreza también se revela a partir de los esfuerzos internacionales que se realizarán a mediano plazo para combatirla. En el preámbulo de la Agenda 2030 para el Desarrollo Sostenible de la Organización de las Naciones Unidas (2015) se reconoce que «la erradicación de la pobreza en todas sus formas y dimensiones, incluida la pobreza extrema, es el mayor desafío a que se enfrenta el mundo». En ella se expresa la aspiración por «un mundo sin pobreza, hambre, enfermedades ni privaciones» (punto 7), se afirma que «miles de millones de nuestros ciudadanos siguen viviendo en la pobreza y privados de una vida digna» (punto 14) y se traza como primer objetivo de desarrollo sostenible el de "poner fin a la pobreza en todas sus formas y en todo el mundo» ${ }^{4}$. Pero enfatiza que la reducción de la pobreza debe ser «en todas sus dimensiones con arreglo

2 Sirva como ejemplo el «concepto fundamental de pobreza» al que alude Smeeding (2016). Este concepto se refiere a "tener muy pocos recursos o capacidades para participar plenamente en una sociedad» (ibid.: 21).

3 Cabe colocar dentro de las afortunadas excepciones a C. Santiago Nino (1995) y G. Ramírez Cleves (2009).

4 De hecho, según el punto 1.1 del objetivo aludido, para el 2030 se pretende «erradicar para todas las personas y en todo el mundo la pobreza extrema». 
a las definiciones nacionales» (objetivo 1.2) y muestra una orientación por un enfoque multidimensional del problema. Desde el derecho, esto haría relevante, cuanto menos, su conceptualización y su análisis vinculado con el principio de igualdad, pues eso permitiría detectar la discriminación en las acciones que se tomen ${ }^{5}$.

Así, este artículo tiene por objeto determinar que la condición de pobreza puede considerarse como una categoría sospechosa de discriminación a la luz de la $\mathrm{CADH}$ y de las constituciones de América Latina, toda vez que la primera prevé el deber de respetar y garantizar los derechos humanos de todas las personas, sin discriminación por su "posición económica» (art. 1.1), mientras que las segundas reconocen cláusulas de igualdad, disposiciones de las que derivaría una norma regulativa — prohibición de discriminaciónque permite la adscripción de esa condición como una de tales categorías.

Con el fin de lograr ese objetivo en la investigación, primero se explorará el concepto de pobreza y se expondrá el estado de cosas existente en América Latina en relación con ella. Luego, se brindarán las razones por las que la condición de pobreza puede considerarse como una categoría sospechosa de discriminación según la $\mathrm{CADH}$. A continuación, desde una perspectiva del derecho interno, se determinará cómo la igualdad, en tanto principio —norma regulativa - reconocido por las constituciones latinoamericanas, se traduce en la prohibición de discriminación de cualquier persona, máxime las que estén comprendidas en categorías sospechosas, concepto que es definido por los tribunales internos de forma no taxativa y dentro del que se incluiría a la pobreza. Finalmente, se fijarán las consecuencias inmediatas de considerar a la pobreza como una categoría sospechosa de discriminación, con cierto énfasis en su utilidad en el contexto de la pandemia por la COVID-19.

\section{POBREZA EN LATINOAMÉRICA}

\section{SOBRE EL CONCEPTO DE POBREZA}

Como se adelantó en la introducción, hay más de un concepto posible de pobreza (Ramírez Cleves, 2009: 11-14; Greve, 2020: 21-22; Smeeding, 2016: 21-23). Ramírez Cleves (2009: 11-14) retoma cinco de ellos. Primero, uno económico —usado por el FMI y Banco Mundial—, donde se define a

5 Como afirman Beck et al., es crucial determinar la naturaleza y extensión de la pobreza, puesto que su definición informa las políticas públicas y motiva la acción política (2020: 2). 
partir de un estándar mínimo de ingreso. En segundo lugar, un concepto a partir de las capacidades — popularizado por Amartya Sen, donde también podría incluirse a Angel (2016: 663-665) —, que afirma que los elementos que considerar no son solo los económicos, sino también la capacidad de las personas para vivir una vida larga y saludable y para tomar decisiones libres e informadas - considera factores como analfabetismo, desnutrición, enfermedades infecciosas previsibles, esperanza de vida- Tercero, la pobreza como exclusión social. Para la Comisión Europea, es el proceso mediante el cual los individuos o grupos sociales son total o parcialmente excluidos de una participación plena en la sociedad en que viven: nula o poca influencia política, exclusión de discusiones y debates e imposibilidad de exponer sus necesidades y prioridades.

En cuarto lugar, un concepto simbiótico entre el segundo y tercero, el de pobreza como una situación de vulnerabilidad, es decir, la dificultad para controlar o contrarrestar las fuerzas que moldean el propio destino y para controlar las que modelan un proyecto de vida. Finalmente, está el concepto de los pobres sobre la pobreza. El estudio The voice of the poor de Deepa Narayan lo hizo conocido. En él, quienes la padecen la definieron como la presencia de muchos factores interrelacionados: dependencia, inseguridad, inestabilidad, injusticia, falta de poder y un correlativo efecto sicológico de angustia, ansiedad, temor, sensación de inferioridad y humillación (Ramírez Cleves, 2009: 13-14).

Debido a esta dificultad de conceptualización, algunos autores optan por ofrecer aproximaciones básicas. En general, puede decirse que la noción de pobreza está vinculada con la de "privaciones o carencias» en aspectos esenciales para la vida de una persona (Malem Seña, 2017: 23). Aunque varía el criterio de selección de tales aspectos, usualmente se ha usado el criterio económico, ya sea de manera exclusiva o en conjunción con otros ${ }^{6}$. De hecho, la métrica monetaria sigue siendo el estándar más conocido y usado para medir la pobreza

6 Por mencionar algunos casos, debe retomarse el concepto de pobreza usualmente utilizado por el FMI y Banco Mundial (Ramírez Cleves, 2009: 11). También, muchas de las voces autorizadas en la materia toman muy en cuenta el factor económico al referirse a ella, como Beck, Hahn y Lepenies (2020: 2) y Smeeding (2016: 2225). De igual forma, desde que finalizó la Segunda Guerra Mundial, la economía del desarrollo — development economics - , con un enfoque orientado hacia lo monetario, ha conducido sus esfuerzos al análisis de soluciones para que los países pobres puedan escapar de su atraso económico (Andersson y Axelsson, 2016: 3-4). También, desde una perspectiva histórica, el primer estudio que intentó medir la pobreza, el de Rowntree, que tuvo lugar en 1899 en York (Reino Unido), la midió considerando «el gasto requerido para comprar los nutrientes necesarios al menor costo posible» 
(Beck et al., 2020: 4-5). Entonces, si el ingreso en dinero de una persona es un criterio de identificación usual y ampliamente difundido, es útil conocer los estándares de medición de la pobreza a partir de él (sobre medición de la pobreza, Smeeding, 2016: 21-46; Angel, 2016: 663-665; Greve, 2020: 9-30; Beck et al., 2020: 4-9; Malem Seña, 2017: 21-35). Para Malem Seña (2017: 24-26), bajo este criterio la cuestión opera así:

a) Usualmente se entiende que una persona es pobre cuando se sitúa por debajo de una línea de ingreso mínimo, que puede fijarse en términos absolutos - lo es quien no alcanza determinados ingresos-, relativos - lo es quien no alcanza un porcentaje determinado del ingreso medio de las personas de un país, como, por ejemplo, el $50 \%$ - o a partir del costo de la cesta básica - lo es quien no logra el ingreso para que él o su familia puedan adquirir los alimentos que la componen-. En este último caso, esto marca la «línea de indigencia».

b) Cuando se toma como punto de partida el costo de la canasta básica, a la línea de indigencia se le completa con el coeficiente de Engel. Esto implica que a dicho costo se le suman los gastos por asuntos como vivienda, educación, transporte o salud. Con este total se fija la «línea de pobreza por ingresos» que ha de servir como parámetro.

Y es que el ser humano necesita de ciertos bienes y recursos para asegurar su supervivencia. Más aún, los necesita para tener una vida digna, que va más allá de la mera sobrevivencia, pues, por ejemplo, puede ocurrir que las condiciones de vida necesarias para estar vivo no sean suficientes para estar sano $^{7}$ (Bilchitz, 2017: 76-77). Para el caso, los niños de hogares pobres son menos saludables y poseen un menor desarrollo cognitivo, logros escolares y bienestar emocional (Iceland, 2003: 2-3); y no solo eso, son conscientes de que son pobres y del impacto que esto tiene en sus vidas en términos de exclusión social, carencias monetarias y costos emocionales (Schweiger y Graf, 2015: 109) ${ }^{8}$. La pobreza también incide en la expectativa de vida

(Greve, 2020: 12-13), de manera que hay una longeva historia científica en considerar el criterio económico en estudios vinculados con la pobreza y su medición.

7 Ocurre que lo que alguien necesita comer para vivir no es suficiente para estar libre de desnutrición.

8 Schweiger y Graf (2015: 109) retoman un interesante estudio cualitativo de Tess Ridge sobre la pobreza infantil. De acuerdo con sus hallazgos, además de ser conscientes de su condición, los niños de hogares pobres se preocupan por los ingresos de su familia y saben que poseen menos recursos y bienes que los demás. Aunque valoran la amistad, tienen problemas para hacer amigos y conservarlos. Además, refieren que 
—sobrevivencia- en sí misma. La Organización Mundial de la Salud refiere que «un niño nacido en 2012 en un país de ingresos altos tiene una esperanza de vida de 75,8 años, o sea, más de 15 años más que un niño nacido en un país de ingresos bajos (60,2 años). Para las niñas la diferencia es aún mayor: 18,9 años más en los países de ingresos altos (82,0 años) que en los de ingresos bajos (63,1 años)» (2014: 7).

De hecho, vista en términos económico-jurídicos, también influye perniciosamente en los derechos humanos y fundamentales. Por ejemplo, incide en los derechos a un juicio justo o debido proceso, voto, libertad de

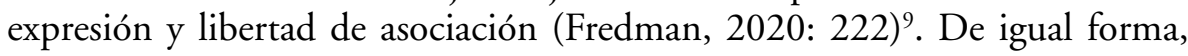
la insatisfacción plena de las necesidades básicas o las carencias económicas también se reflejan en la posibilidad real de hacer efectivas las prestaciones que exigen otros derechos fundamentales (Häberle, 2019: 132). Y si toda persona, con independencia de su posición social, debe poseer igual posibilidad de autorrealización y disfrute de tales derechos (Baldassarre, 2004: 78-79), se tiene la obligación de satisfacer las expectativas de organización, procedimiento y prestación que sean necesarias para que no existan barreras para la consecución de una igual libertad — por ejemplo, la erradicación de la pobreza-, pues solo así todos contarían con los presupuestos y condiciones mínimas para su disfrute pleno (Añón, 2008: 102).

\section{EL ESTADO DE COSAS EN AMÉRICA LATINA}

En Latinoamérica la pobreza es un problema social de tal amplitud que no solo instituciones como el FMI, CEPAL y Banco Mundial se han ocupado de él. Desde el derecho, la CIDH ha elaborado el Informe sobre pobreza $y$ derechos humanos en las Américas, donde recoge las dificultades para conceptualizarla —ya referidas_-, un abordaje a partir de los derechos humanos y las

sufren de acoso por sus pares, que son discriminados por los adultos y que se sienten estigmatizados, excluidos y de poco valor. El estudio de Ridge, citado por Schweiger y Graf, también menciona que esos niños se sienten frustrados y enojados por tener menos bienestar económico que los demás y que sienten miedo respecto de su futuro.

9 Si se retoma el caso de la libertad de expresión, al ser un derecho que permite la búsqueda, recepción y difusión de informaciones e ideas de toda índole y por cualquier medio (art. 13.1 CADH), las privaciones económicas, que impiden el acceso a internet o a dispositivos electrónicos por sus considerables costos para una persona con ingresos por debajo de la línea de pobreza, tendrían un reflejo negativo en la posibilidad de ejercer ese derecho por medio de entornos digitales (por ejemplo, reivindicar expectativas o expresar ideas a través de hashtags de Twitter o posts de Facebook, algo muy común en las sociedades actuales). 
cifras generales en la región (2017: 21-43). En cuanto a este último punto, la CIDH destaca que "América Latina revela actualmente una tendencia al estancamiento en los esfuerzos por la reducción de la pobreza» (ibid.: 42); que la región sigue siendo la más desigual del mundo —un $10 \%$ de población acaparaba, para entonces, el $71 \%$ de la riqueza, a la vez que la mitad de la población se encontraba en situación de pobreza y acumulaba solamente el 3,2\%- (ibid.: 43), y que algunos países, como Haití, tenían un porcentaje de $77 \%$ de la población viviendo bajo la línea de pobreza (ibid.: 43).

Por su parte, CEPAL (2019: 96) refiere que «en 2018, alrededor del $30,1 \%$ de la población de América Latina estaba bajo la línea de pobreza, mientras que un $10,7 \%$ se encontraba bajo el umbral de la pobreza extrema», y "para 2019 se proyecta un aumento de la pobreza y de la pobreza extrema en el agregado regional, ya que llegarían a tasas del $30,8 \%$ y del $11,5 \%$, respectivamente». Así, en la región la pobreza es un obstáculo para el goce de las condiciones básicas para autodeterminarse con libertad ${ }^{10}$, porque no solo supone que las personas parten de posiciones desiguales para la obtención de bienes, sino que también es el resultado de una distribución inequitativa de ellos ${ }^{11}$. A su vez, «la pertenencia a distintos estratos o clases sociales constituye uno de los ejes estructurantes de la matriz de la desigualdad social [...]» (ibid.: 41).

Según informes especiales recientes de CEPAL, la región latinoamericana - en el plano económico - tuvo que enfrentarse a la pandemia por la COVID-19 desde "una posición más débil que el resto del mundo» (CEPAL, 2020a: 5). Por ejemplo, la pandemia ha hecho visible la notable brecha en el acceso y uso de internet entre las personas pobres y quienes no lo son, lo cual ha tenido repercusiones en la posibilidad de teletrabajo y en la educación

10 Esto conduce a hablar de la necesidad de «igualdad entre todos los seres humanos en los recursos adecuados para satisfacer las necesidades básicas de forma que permitan a todos y cada uno desarrollar de forma equiparablemente autónoma y libre su propio plan de vida» (Hierro, 2009: 111).

11 Que la pobreza suponga un problema estructural en el que puede identificarse una deficiencia distributiva y otra de resultados implica que puede ser abordada desde dos teorías políticas sobre la igualdad. La primera es la igualdad de oportunidades, que defiende un enfoque en el que hay que ocuparse de que todos los participantes de un proceso deliberativo y de distribución de bienes tengan igualdad en el punto de partida, pues todos deben poder luchar por lo vitalmente significativo partiendo de posiciones iguales (Bobbio, 1993: 78). La segunda es la igualdad de resultados, en la que el enfoque se centra en que exista «un esquema de distribución que brinde a los participantes la misma cantidad de prerrogativas distribuidas como resultado final» (Keren-Paz, 2016: 26). 
(CEPAL, 2020b: 2-11; CEPAL, 2020c: 5-8) ${ }^{12}$. También ha permitido advertir cómo las consecuencias perniciosas del desempleo se manifiestan de forma distinta en ambos grupos, ya que «los efectos del desempleo afectarán de manera desproporcionada a los pobres y a los estratos vulnerables de ingresos medios» (CEPAL, 2020a: 10).

CEPAL adelanta la posibilidad de que la tasa de pobreza aumente en un $4,4 \%$ y la de pobreza extrema en un 2,5\%. Esto significaría un incremento de 28,7 millones de personas pobres y 16 millones de personas en pobreza extrema (CEPAL, 2020d: 15-16). Frente a este pronóstico desasosegante, United Nations Development Programme (PNUD, por sus siglas en español) y CEPAL han propuesto que se garantice una renta básica temporal en la región para mitigar la crisis actual y venidera, con el fin de que nadie tenga ingresos por debajo de la línea de pobreza (PNUD, 2020: 5-12) ${ }^{13}$. El derecho a la renta básica, protección frente a la pobreza o mínimo vital es «el otorgamiento de una prestación económica a toda persona que carezca de los medios necesarios para llevar una vida digna» (Escobar Roca, 2018: 130).

\section{CONDICIÓN DE POBREZA COMO CATEGORÍA SOSPECHOSA DE DISCRIMINACIÓN A LA LUZ DE LA CONVENCIÓN AMERICANA SOBRE DERECHOS HUMANOS}

\section{DOS CONCEPTOS BÁSICOS}

Hay dos conceptos básicos relacionados con este tema: el de categorías sospechosas de discriminación y el de aporofobia. Sobre el primero, el Tribunal Constitucional de Perú ha sostenido:

12 En El Salvador, los medios de comunicación advierten de los problemas educativos que la falta de acceso a la tecnología e internet ha generado durante la pandemia por la COVID-19. Estos reseñan que «durante los últimos cinco meses, marcados por la pandemia del coronavirus, muchos docentes están preocupados y hacen malabares para lograr que sus alumnos lleguen al final del curso, dados los problemas económicos y acceso a la tecnología que estos y sus familias enfrentan» (disponible en: https://bit. ly/3xIeJ80). De igual manera, informan que durante la emergencia sanitaria la falta de herramientas y dinero ha provocado deserción estudiantil en algunos centros de educación (disponible en: https://bit.ly/2SivzKd). Por su parte, en el informe citado de CEPAL se afirma que «en 2018, casi 23 millones de los hogares — la mitad de los hogares sin conexión a internet- se ubicaban en los dos quintiles más bajos de la distribución del ingreso (quintiles I y II)».

13 También pueden consultarse noticias relacionadas con esto en: https://bit.ly/3aYfK1Q. 
Se entiende por "categorías sospechosas» o «especialmente odiosas» a aquellos criterios de clasificación que aluden a determinados grupos sociales que han sido históricamente discriminados y que, por ende, merecen recibir una tutela especial o diferenciada de parte del ordenamiento jurídico. En este caso, dicha protección cualificada consiste en establecer que toda distinción que se funde en alguno de estos criterios expresamente vedados, estará afecta a una presunción de inconstitucionalidad, la cual sólo podrá ser desvirtuada a través de una justificación estricta, objetiva y razonable ${ }^{14}$.

Esta caracterización realizada por el Tribunal Constitucional de Perú es similar a la que han hecho otros tribunales constitucionales de la región latinoamericana. A manera de ejemplo, puede mencionarse la que ha realizado la Corte Constitucional de Colombia ${ }^{15}$, la Corte Constitucional de Ecuador ${ }^{16}$ y la Sala de lo Constitucional de El Salvador ${ }^{17}$. Además, es consecuente con lo que doctrinariamente se ha entendido por una categoría o clasificación sospechosa: "Aquellos supuestos en los que el criterio o rasgo de diferenciación de trato jurídico es la raza, el sexo, la religión, la ideología, el nacimiento o cualquier otro que la experiencia histórica evidencie como gravemente odioso para la dignidad de la persona» (Bilbao Ubillos y Rey Martínez, 2003: 111).

En lo que respecta a la aporofobia, dicho concepto ha sido introducido en el plano filosófico por Adela Cortina. Con él se designa al «rechazo, aversión,

14 Tribunal Constitucional de Perú, Sentencia de 3 de septiembre de 2010, Exp. n. ${ }^{\circ}$ 2317-2010-AA/TC, fundamento jurídico 32.

15 Corte Constitucional de Colombia, Sentencia de 22 de febrero de 2017, C-115/17, II D 28. Para la Corte, «el carácter sospechoso de un criterio de diferenciación hace referencia a las categorías que "(i) se fundan en rasgos permanentes de las personas, de las cuales estas no pueden prescindir por voluntad propia a riesgo de perder su identidad; (ii) esas características han estado sometidas, históricamente, a patrones de valoración cultural que tienden a menospreciarlas, y, (iii) no constituyen, per $s e$, criterios con base en los cuales sea posible efectuar una distribución o reparto racionales y equitativos de bienes, derechos o cargas sociales"”.

16 Corte Constitucional de Ecuador, Sentencia de 7 de septiembre de 2016, n. ${ }^{\circ}$ 292-16-SEP-CC. La Corte Constitucional precisa que esas categorías «son aquellas utilizadas para realizar tratos "diferentes" respecto de ciertos grupos o personas vulnerables que no resultan razonables y proporcionales, cuyo uso ha estado históricamente asociado a prácticas que tienden a colocar en situaciones de desventaja o desprotección a grupos de personas generalmente marginados».

17 Sala de lo Constitucional de El Salvador, Sentencia de 10 de agosto de 2015, inconstitucionalidad 112-2012, considerando III.1: La Sala de lo Constitucional afirma que «se trata de situaciones, criterios o factores que históricamente han sido causas comunes de tratos diferenciados». 
temor y desprecio hacia el pobre, hacia el desamparado que, al menos en apariencia, no puede devolver nada bueno a cambio» (Cortina, 2017: 14). La mera existencia de esta expresión evidencia que existe una realidad meritoria de atención, y es un buen punto de partida para analizar si el derecho invita a tener alguna consideración particular con las personas en condición de pobreza, pues implica que su discriminación es tan recurrente que necesita de una palabra que la designe.

\section{CONDICIÓN DE POBREZA COMO CATEGORÍA SOSPECHOSA DE DISCRIMINACIÓN EN LA CONVENCIÓN AMERICANA SOBRE DERECHOS HUMANOS}

El art. 1.1 de la $\mathrm{CADH}$ — uno de los instrumentos principales en materia de derechos humanos para Latinoamérica- establece el deber de respetar y garantizar los derechos y libertades reconocidos en ella a toda persona sujeta a la jurisdicción de un Estado, sin discriminación alguna por motivos de raza, color, sexo, idioma, religión, opiniones políticas o de cualquier otra índole, origen nacional o social, posición económica, nacimiento o cualquier otra condición social. La CIDH ha dicho que todos los motivos de discriminación mencionados en esta disposición son categorías sospechosas. En concreto, afirma:

Cuando las distinciones se encuentran basadas en ciertas categorías mencionadas expresamente en las cláusulas de no discriminación de los tratados internacionales de derechos humanos, existe un consenso en el sentido de que el análisis que se utiliza para medir la razonabilidad de la diferencia de trato, es especialmente estricto. Esto se debe a que por su naturaleza, dichas categorías son consideradas «sospechosas» y por lo tanto se presume que la distinción es incompatible con la Convención Americana ${ }^{18}$.

De entre los criterios mencionados interesa la discriminación por posición económica, pues es en él en donde podría ubicarse a la pobreza para poderla calificar como categoría sospechosa. Como se dijo en el apartado II.1, hay más de un concepto de pobreza, pero en todos es relevante el criterio económico en mayor o menor medida, a la vez que la métrica monetaria continúa siendo el estándar más conocido y usado para medirla (Lang, 2007: 37-39; Beck et al., 2020: 4-5). De hecho, en el ámbito específico de América Latina, aunque se reconoce que la pobreza es un concepto multidimensional, el enfoque monetario

18 Informe $n .^{\circ} 81 / 13$, caso 12743, fondo. Homero Flor Freire, Ecuador, 4 de noviembre de 2013, párrafo 98. 
o por ingresos es ampliamente utilizado por los Estados -Argentina, Brasil, Colombia, El Salvador, Guatemala, Honduras, Jamaica, Panamá, Paraguay, Surinam y Uruguay- (CIDH, 2017: 26-33). Desde luego, debe reconocerse la necesidad «de que los países dispongan de mediciones multidimensionales de la pobreza» (CIDH, 2017: 33), pero este dato sugiere la idiosincrasia prevalente en la región: se ve a la pobreza como un tema económico ${ }^{19}$.

De forma que las privaciones y carencias en términos de ingresos y la consecuente "posición económica» que se ocupa en la sociedad se vinculan con cualquiera de los conceptos de pobreza que se han referido en este texto, que son los más difundidos; a la vez, al ser común que en Latinoamérica se mida a la pobreza desde una perspectiva económica, tiende a generarse un convencionalismo social en torno a lo que entendemos por personas pobres a partir de ella, y con ello nace el germen de posibles desigualdades estructurales.

En adición a esta posibilidad interpretativa, también debe valorarse que incluso si la pobreza no fuese definida como un asunto de posición económica, su difícil encaje con las demás categorías sospechosas de discriminación directamente estatuidas en el art. 1.1 CADH no sería razón alguna para rechazar que es una de ellas. Si según la doctrina y jurisprudencia citadas en el apartado III.1, lo decisivo no es la textualidad, sino el hecho de que se trate de grupos sociales que hayan sido históricamente discriminados, entonces la larga data de aporofobia en América Latina debería bastar para considerarla como tal (CIDH, 2020: 7; CIDH, 2017: 12). Y esto no solo por lo que los Estados hacen y que se podría calificar como discriminatorio, sino también por sus deudas históricas y aquiescencia frente a dicha problemática social —una falta al deber de promoción y protección que impone la igualdad- (Nino, 1995: 53-135; Haugen y Boutros, 2014: XV).

Conviene detenerse en la afirmación realizada en el párrafo anterior. Cuando aquí se alude a una discriminación histórica, se hace considerando un concepto estructural de la desigualdad. En casos de desigualdad estructural - un concepto alejado de las concepciones liberales de la igualdad- «resulta relevante la incorporación de datos históricos y sociales que dé cuenta del fenómeno de sometimiento y exclusión sistemática a la que se encuentran sometidos amplios sectores de la sociedad» (Saba, 2005: 125). Tal concepto asume que el derecho no debe volver la vista a otro lado frente a las relaciones que se producen entre grupos sociales. Por ejemplo, aunque no haya normas que excluyan a las mujeres o pobres del ejercicio

19 Muy probablemente esta sea la razón por la que «la pertenencia a distintos estratos o clases sociales constituye uno de los ejes estructurantes de la matriz de la desigualdad social [...]» (CEPAL, 2019: 41). 
de sus derechos fundamentales, estos en algunos casos son «solamente palabras», pues de facto se les discrimina en derechos como el acceso a cargos públicos, salud o educación (id.).

Todas estas valoraciones no han sido ajenas para la doctrina de la región. En algunos estudios sobre las categorías sospechosas se ha dicho que «existen buenos fundamentos normativos para sostener que la pobreza puede constituir una categoría sospechosa. En tal sentido, entre los motivos especialmente prohibidos de discriminación previstos en diversos instrumentos internacionales de derechos humanos aparece la "posición económica” (Treacy, 2011: 208-209). Vale decir que esto no solo se ha sostenido en el ámbito latinoamericano. Por ejemplo, muchas de las sentencias del tribunal Warren de la Corte Suprema de Estados Unidos calificaron a la riqueza como una categoría sospechosa de discriminación. Su aplicación sirvió para los derechos al voto y al acceso al recurso de apelación en materia penal (Ruiz Miguel, 1996: 62).

Dadas todas las consideraciones precedentes, en este punto interesa destacar que, hasta la fecha, la Corte IDH ha hecho dos afirmaciones de especial importancia sobre la prohibición de discriminar: a) el principio de no discriminación forma parte del jus cogens del derecho internacional ${ }^{20}$, por lo que le resulta aplicable lo dispuesto en los arts. 53, 64 y 71 de la Convención de Viena sobre el Derecho de los Tratados, referidos a la nulidad de los tratados internacionales, y b) el concepto de discriminación puede ser definido de conformidad con la $\mathrm{CADH}$ de la siguiente manera:

Toda distinción, exclusión, restricción o preferencia que se basen en determinados motivos, como la raza, el color, el sexo, el idioma, la religión, la opinión política o de otra índole, el origen nacional o social, la propiedad, el nacimiento o cualquier otra condición social, y que tengan por objeto o por resultado anular o menoscabar el reconocimiento, goce o ejercicio, en condiciones de igualdad, de los derechos humanos y libertades fundamentales de todas las personas ${ }^{21}$.

La existencia de estos estándares normativos interamericanos lleva a que la condición de pobreza se considere, para todos los efectos, como una categoría sospechosa de discriminación en todos los países de América Latina que han suscrito la $\mathrm{CADH}$, en especial en aquellos que cuentan con un

20 Corte IDH. Condición jurídica y derechos de los migrantes indocumentados. Opinión Consultiva OC-18/03, de 17 de septiembre de 2003, párrafo 101.

21 Corte IDH. Sentencia de 9 de marzo de 2018 (fondo, reparaciones y costas), Caso Ramírez Escobar y otros vs. Guatemala, párrafo 269. 
bloque de constitucionalidad ${ }^{22}$. Esto se debe al control de convencionalidad, cuyo génesis fue la sentencia de la Corte IDH en el caso Almonacid Arellano $y$ otros vs. Chile, en virtud del cual todos los Estados parte de la CADH están obligados a interpretar su derecho interno de conformidad con ella (Ferrer Mac-Gregor, 2014: 233). En adición a esta obligación, los tribunales constitucionales latinoamericanos suelen ser receptivos al uso de la $\mathrm{CADH}$ y de los precedentes u opiniones de la CIDH y Corte IDH (Fix-Zamudio, 2013: 744).

\section{EL PRINCIPIO DE IGUALDAD EN EL DERECHO INTERNO LATINOAMERICANO Y LA PROHIBICIÓN DE APOROFOBIA}

\section{EL PRINCIPIO DE IGUALDAD Y LA PROHIBICIÓN DE DISCRIMINACIÓN EN LAS CONSTITUCIONES DE AMÉRICA LATINA}

En principio, lo dicho en el apartado anterior debería tener el peso suficiente para que los Estados tuviesen que tomar en cuenta la prohibición de discriminación por pobreza en su derecho interno — políticas públicas, decisiones judiciales, creación de normas, etc.-. Pero, por la importancia del tema, no es sobreabundante argumentar las razones por las que dicha prohibición también tiene cabida en las constituciones de los países de América Latina, en tanto que reconocen el principio de igualdad del que esta derivaría.

Como es sabido, la igualdad «es una aspiración irrenunciable del constitucionalismo» (Solozabal Echavarria, 2013: 75). Aunque en los albores del constitucionalismo latinoamericano la protección de las minorías se relacionaba con una protección de los ricos que condujo a la exclusión social y política - producto de un pacto liberal-conservador- (Gargarella, 2014a: 62-63), en la actualidad el reconocimiento del principio de igualdad ha

22 En general, en América Latina se emplea la expresión «bloque de constitucionalidad» para referirse a un conjunto de disposiciones que se consideran como parte material de la Constitución, aunque formalmente no lo sean (Ferrer Mac-Gregor, 2013: 637). Por ejemplo, el art. 75.22 de la Constitución de Argentina dispone que «tienen jerarquía constitucional» una serie de tratados internacionales de derechos humanos —entre ellos, la Convención Americana sobre Derechos Humanos-. Esta es una acepción distinta de la usada en España, pues en tal país el «bloque de constitucionalidad» es la serie de normas constitucionales y legislativas que sirven para delimitar las competencias del Estado y de las comunidades autónomas, o para regular y armonizar el ejercicio de las que han sido conferidas a dichas comunidades (Rubio Llorente, 1989: 15). 
pasado a ser un lugar común en las constituciones regionales al lado del de los derechos sociales, que demandan la «satisfacción de necesidades básicas de las personas en ámbitos como el trabajo, la vivienda, la salud, la alimentación o la educación» (Pisarello, 2007: 11). De forma sintética e ilustrativa, pueden citarse estas constituciones de Latinoamérica:

\section{Tabla 1. Constituciones latinoamericanas. Reconocimiento de principio de igualdad}

\begin{tabular}{|c|c|}
\hline País & Disposición constitucional \\
\hline Argentina & Art. $16^{23}$ \\
\hline Bolivia & Art. $14 \mathrm{II}^{24}$ \\
\hline Chile & Art. 19 ordinal $2 .^{\text {.25 }}$ \\
\hline Colombia & Art. $13^{26}$ \\
\hline Costa Rica & Art. $33^{27}$ \\
\hline Ecuador & Art. $11.2^{28}$ \\
\hline El Salvador & Art. $3^{29}$ \\
\hline Guatemala & Art. $4^{30}$ \\
\hline Honduras & Art. $60^{31}$ \\
\hline México & Art. $1^{32}$ \\
\hline Perú & Art. $2.2^{33}$ \\
\hline Uruguay & Art. $8^{34}$ \\
\hline Venezuela & Art. $21^{35}$ \\
\hline
\end{tabular}

Fuente: elaboración propia. Este solo es un listado ilustrativo, pues hay más países que

23 Disponible en: https://bit.ly/3nTh8s1 (acceso: 24 de marzo de 2021).

24 Disponible en: https://bit.ly/3aXbQ9v (acceso: 24 de marzo de 2021).

25 Disponible en: https://bit.ly/2QHfVYD (acceso: 24 de marzo de 2021).

26 Disponible en: https://bit.ly/3uilDyv (acceso: 24 de marzo de 2021).

27 Disponible en: https://bit.ly/33c2cve (acceso: 24 de marzo de 2021).

28 Disponible en: https://bit.ly/3eR9gTG (acceso: 24 de marzo de 2021).

29 Disponible en: https://bit.ly/3vDN3Pw (acceso: 24 de marzo de 2021).

30 Disponible en: https://bit.ly/2Rkulh4 (acceso: 24 de marzo de 2021).

31 Disponible en: https://bit.ly/3aZtLfH (acceso: 24 de marzo de 2021).

32 Disponible en: https://bit.ly/3aXZH40 (acceso: 24 de marzo de 2021).

33 Disponible en: https://bit.ly/3aYzL8y (acceso: 24 de marzo de 2021).

34 Disponible en: https://bit.ly/3h3gnLz (acceso: 24 de marzo de 2021).

35 Disponible en: https://bit.ly/3eah2ca (acceso: 24 de marzo de 2021). 
incorporan el principio de igualdad en sus constituciones; y dentro de los citados, su reconocimiento no siempre se limita a una disposición.

De entre las constituciones mencionadas, las de Bolivia, Ecuador, México, Perú y Venezuela admiten, de forma textual, la adscripción de la norma prohibitiva de la aporofobia, debido a que prohíben discriminar a las personas por su «condición económica o social» (Bolivia), "condición socioeconómica» (Ecuador, una de las constituciones con más categorías sospechosas expresamente reconocidas), "condición social» (México y Venezuela) o "condición económica» (Perú). Para interpretar esas expresiones, cabría retomar los argumentos del apartado III.2 sobre la posición económica como categoría sospechosa en la CADH. Otras constituciones (Colombia, Costa Rica, Honduras y El Salvador) prevén la prohibición de discriminación sin calificar expresamente a la pobreza como criterio sospechoso. No obstante, esto se profundizará en el subapartado que sigue.

\section{EL PRINCIPIO DE IGUALDAD COMO NORMA REGULATIVA: LA PROHIBICIÓN DE DISCRIMINACIÓN POR CONDICIÓN DE POBREZA (APOROFOBIA) EN EL DERECHO INTERNO LATINOAMERICANO}

Desde el ámbito jurídico, la igualdad es a veces vista como una categoría a la que corresponde una triple naturaleza de valor, principio y derecho (Díaz de Valdés, 2015: 154) ${ }^{36}$. Esta caracterización triádica de la igualdad es aceptada por algunos tribunales constitucionales de América Latina ${ }^{37}$. La igualdad como principio se concreta en cuatro mandatos: a) tratar de forma idéntica a quienes estén en situaciones idénticas; b) tratar de forma diferenciada a quienes estén en condiciones que no comparten ningún elemento común; c) tratar de forma paritaria a quienes estén en circunstancias que tienen similitudes y diferencias,

$36 \mathrm{Al}$ decir que la igualdad posee este carácter triádico se reconoce que, como enunciado jurídico, tiene un carácter práctico: normativo cuando se trata de la igualdad como principio o derecho y valorativo cuando se trata de la igualdad como valor (Atienza y Ruiz Manero, 2016: 189-191).

37 Por ejemplo, véase: a) El Salvador: Sala de lo Constitucional, Sentencia de 23 de diciembre de 2016, inconstitucionalidad 156-2012, considerando V; b) Colombia: Corte Constitucional, Sentencia de 13 de octubre de 2010, C-818/10, II 5; y c) Perú: Tribunal Constitucional, Sentencia de 14 de octubre de 2009, Exp. n. ${ }^{\circ} 01604-$ 2009-PA/TC, fundamentos jurídicos 4 a 11. Una aproximación filosófica a la primera de esas perspectivas — igualdad como valor - permite distinguir tres acepciones: igualdad ante la ley, igualdad de oportunidades e igualdad en prestaciones sociales universalizadas. Esas acepciones convergen en que todas son igualdad en dignidad y, por ello, deben ser igualmente consideradas y respetadas (Cortina, 1997: 80) 
pero en las que las primeras son más relevantes que las segundas; y d) tratar de forma diferente a quienes estén en circunstancias que poseen similitudes y diferencias, pero en las que las segundas son más relevantes que las primeras (Bernal Pulido, 2008: 257) ${ }^{38}$.

De las tres naturalezas, solo el principio o derecho de igualdad constituyen normas regulativas, entendidas como normas que contienen permisos, mandatos o prohibiciones $^{39}$ (Atienza, 2013: 88-95; Vilajosana, 2010: 20-24). Por el carácter más concreto del segundo (Alexy, 2012: 379-382), interesa destacar el contenido básico del principio de igualdad que reconocen las constituciones de Latinoamérica. En virtud de los mandatos que derivan de dicho principio, apuntados en el párrafo previo, puede decirse que en el lenguaje constitucional este posee dos pilares medulares: la prohibición de discriminación y el deber de promoción y protección de quienes estén en alguna posición desfavorecida. La primera es una especie de manifestación del mandato de trato paritario - letras a y c- , y el segundo lo es del mandato de trato diferenciado - letras b y d- (Bernal Pulido, 2008: 258-259).

Esta manifestación dual de prohibición y deber es congruente con las obligaciones estatales de abstención o de prestación — hacer o no hacer- que generan los principios y los derechos fundamentales (Sarlet, 2019: 360-361), que ahora ya no vinculan al Estado únicamente por un impedimento de vulnerarlos, sino que también le exigen cumplir con ciertas obligaciones

38 Para Carlos Bernal, el principio de igualdad genera el deber estatal de tratar a las personas de forma tal que las cargas y ventajas sociales estén distribuidas equitativamente entre sí. Los mandatos antedichos serían las concreciones de ese deber. Esta conceptualización del principio de igualdad y de sus concreciones ha sido utilizada por algunos tribunales de Latinoamérica, por ejemplo, la Sala de lo Constitucional de El Salvador (Sentencia de 9 de octubre de 2017, inconstitucionalidad 44-2015/103-2016, considerando III 1, entre otras) y la Corte Constitucional de Colombia (Sentencia de 13 de septiembre de 2017, C-571/17, II D 21).

39 La teoría del derecho ha adoptado la distinción de las normas jurídicas en constitutivas y regulativas. En Latinoamérica, esta distinción permeó en la jurisprudencia constitucional salvadoreña, pues la Sala de lo Constitucional ha hecho uso de ella en numerosas resoluciones. Por mencionar algunas, la Sentencia de 28 de mayo de 2018, inconstitucionalidad 146-2014/107-2017, considerando III 2; y la Sentencia de 19 de agosto de 2020, controversia 8-2020, considerando VII 2. En la última de estas sentencias, el tribunal sostuvo que «las [normas constitutivas] establecen las condiciones exigibles para la producción y existencia de situaciones jurídicas o de resultados institucionales y son condición necesaria para la producción de las consecuencias jurídicas a que se refieren. Las [normas regulativas] son las que contienen permisos, mandatos o prohibiciones para los sujetos destinatarios del Derecho». 
de hacer que garanticen que los individuos sean capaces de ejercerlos (Barak, 2017: 461-462). Así, en lo que aquí concierne, todos los órganos del Estado deben evitar la discriminación —abstención-y favorecer la consecución de la igualdad real de las personas en alguna posición de desventaja — prestación-. El principio de igualdad no es una norma constitutiva que le confiera poder al Estado para adoptar esos cursos de acción: es una norma regulativa que le obliga a hacerlo.

Pues bien, esta prohibición de discriminación opera de forma más intensa cuando se trata de categorías sospechosas. En lo atinente al tema de esta investigación, cabría desdoblar el análisis en dos grupos de constituciones. Por un lado, las que prohíben expresamente cualquier clase de discriminación basada en la condición económica de las personas, es decir, las que proscriben la aporofobia y la estatuyen como una categoría sospechosa de discriminación, retomando lo expuesto en los apartados III.2 y IV.1. Dentro de ese grupo se encontrarían las constituciones de Bolivia, Ecuador, México, Perú y Venezuela. Por otro lado, las que no contienen una cláusula expresa en la que la condición de pobreza se considere como categoría sospechosa, como las de Colombia, Honduras, El Salvador y Costa Rica - las tres primeras sí prevén expresamente otras de esas categorías, pero no la pobreza-.

En las constituciones del primer grupo es menos problemático sostener que desde el derecho interno la condición de pobreza puede calificarse como un criterio sospechoso de discriminación. En las del segundo grupo, aunque la prohibición de aporofobia no sea una norma directamente estatuida, siempre cabe afirmar que es una de estas categorías con base en tres argumentos. El primero es que las constituciones no deben interpretarse de forma textual —ese criterio interpretativo es útil, pero insuficiente- (Díaz Revorio, 2016: 16-24), por lo que la ausencia de una cláusula expresa no constituye impedimento alguno para arribar a esa conclusión. El segundo es que muchos tribunales constitucionales de países en los que las constituciones prevén otras categorías sospechosas, pero no la pobreza, reconocen que se trata de listados no taxativos. Así, la Sala de lo Constitucional de El Salvador ha dicho:

Según nuestra norma primaria, el derecho a la igualdad no se agota en su vertiente de igualdad como comparación con el derecho de otros, sino que implica la consiguiente prohibición de discriminar por las razones señaladas en el art. $3 \mathrm{Cn}$., las cuales no son taxativas, es decir, las causas de discriminación señaladas en la disposición antes 
mencionada son ilustrativas, y no son las únicas por las cuales una persona puede ser discriminada ${ }^{40}$.

A lo anterior se agregaría un tercer argumento, consistente en la necesidad de que las constituciones se interpreten evolutivamente —así lo exigiría su rigidez- (Aguiló Regla, 2012: 242-245). No debe haber una «adoración de lo antiguo» ni renunciarse a una "conversación entre generaciones» (Ackerman, 2011: 105): la de quienes crearon la constitución y la de quienes deben vivir de conformidad con ella ${ }^{41}$. Si para la generación de "los vivos» ya no tienen sentido las palabras de «los muertos» (en paráfrasis de Aguiló), es necesario adaptar el significado de las disposiciones constitucionales para que tengan sentido democrático para los primeros. Y pocas cosas son más identificables con la democracia que el reconocimiento y garantía de los derechos de «los más débiles», es decir, los que están en alguna especie de posición desventajosa (Ferrajoli, 2004: 54-55). En términos empíricos contrastables, en Latinoamérica los pobres están en ese grupo.

40 Sala de lo Constitucional de El Salvador, Sentencia de 9 de diciembre de 2009, amparo 18-2004, considerando IV 1. En igual sentido, Corte Constitucional de Colombia, Sentencia de 26 de octubre de 2016, C-586/16, VI 5.

41 En El Salvador se ha propuesto una solución interesante a la cuestión de la conversación entre generaciones. En la Sentencia de 8 de junio de 2020, inconstitucionalidad 212020 AC, la Sala de lo Constitucional sostuvo que si hubo una situación contextual particular en la redacción de una o varias disposiciones constitucionales o títulos, capítulos o secciones de la constitución "y esta se mantiene en la actualidad, la interpretación debe ser originalista; si la hubo, pero ya no se mantiene o no es relevante para el caso, debe ser evolutiva; y si no la hubo, debe ser también evolutiva». Sin embargo, se ha afirmado que esta es una respuesta solo parcialmente aceptable, en tanto que sí es coherente para los casos en que se trate de conceptos constitucionales densos - con un componente descriptivo y valorativo-, pues el cambio en las situaciones que describen es objetivamente contrastable; pero pareciera producir alguna especie de paradoja en el caso de los conceptos constitucionales ligeros — puramente valorativos— (Vela Ávalos, 2021: 75-77), porque entonces «un TC estaría buscando disipar los problemas democráticos a los que podría conducir el originalismo, pero en realidad podría ser él quien termine por generarlos» (ibid.: 76), debido a que podría ocurrir que la pérdida de sentimiento constitucional no se produzca por la "tiranía de los muertos sobre los vivos», sino porque el tribunal constitucional de que se trate, en uso de su «última palabra en materia constitucional», termine por imponer interpretaciones de la Constitución a las que el pueblo no le encuentre ningún sentido democrático. 


\section{CONSECUENCIAS INMEDIATAS DE CONSIDERAR A LA POBREZA COMO CATEGORÍA SOSPECHOSA DE DISCRIMINACIÓN}

Que la pobreza sea un criterio sospechoso no es una cuestión sin transcendencia alguna. En cualquiera de los modelos del juicio de igualdad - europeo, norteamericano o integrado- es necesario fijar un término de comparación en el que se identifique cuál es la situación jurídica contrapuesta a la que se impugna, es decir, el supuesto de hecho que tiene una consecuencia jurídica que se estima desigual, ya que este término marcará el criterio usado para enjuiciar la medida supuestamente violatoria del principio de igualdad. Vale decir que tal comparación debe ser siempre dentro de la legalidad, porque no existe tal cosa como la igualdad en la ilegalidad (véase Giménez Glück, 2004: 71-77; Bernal Pulido, 2008: 257-283). En los modelos norteamericano e integrado ${ }^{42}$, el establecimiento del término de comparación supone la asunción de un escrutinio de igualdad ${ }^{43}$.

Una vez determinado el término de comparación, el examen de proporcionalidad que va inserto en el test de igualdad se enfrenta a dos escenarios distintos que dependen de si se trata del incumplimiento de una obligación de no hacer - prohibición de discriminación — o de la insatisfacción de una obligación de hacer — deber de promoción y protección-. En el primer escenario la medida se examina desde la vertiente de la proporcionalidad conocida como prohibición de exceso, y en el segundo, de la prohibición de protección deficiente (Montealegre Lynett et al., 2014: 15). Puede existir exceso cuando el sujeto pasivo debió abstenerse de intervenir en un derecho fundamental — discriminar-, pero no lo hizo. Y puede haber protección deficiente cuando el sujeto pasivo tenía una obligación de hacer - promover y proteger-, pero no satisfizo a plenitud la expectativa positiva correspondiente (véase Bernal Pulido, 2014: 1028). Como aquí se analiza la prohibición de discriminación, interesa el primer caso.

42 La Sala de lo Constitucional de El Salvador ha hecho suyo el test integrado de igualdad. Ver la Sentencia de 23 de octubre de 2020, inconstitucionalidad 98-2015, considerando VII.

43 Carlos Bernal Pulido expresa que hay tres clases posibles de escrutinios de igualdad (Bernal Pulido, 2008: 266-271): a) escrutinio débil, que es aquel en el que no entra en juego o consideración ninguna categoría sospechosa de discriminación; b) escrutinio intermedio, en el que hay diferenciaciones que tienen como base una o más de esas categorías, pero con el fin de favorecer a las personas que están comprendidas dentro de ellas; y c) escrutinio estricto, que es aquel en el que hay tratos diferenciados basados en alguna o varias de dichas categorías que afectan negativamente a las personas comprendidas en ellas. 
Si el término de comparación implica que se ha discriminado con base en una categoría sospechosa - para el interés de este artículo, la pobreza-, habría dos consecuencias inmediatas. Primero, la discriminación se presume como inconvencional e inconstitucional. Por ello, según lo ha sostenido la Corte IDH, «se invierte la carga de la prueba, lo que significa que corresponde a la autoridad demostrar que su decisión no tenía un propósito ni un efecto discriminatorio» ${ }^{44}$. Segundo, dada la carga de la argumentación que correspondería al Estado según lo apuntado, este únicamente podría justificar la discriminación realizada si aduce un fin constitucional o convencional imperativo que sustente su aceptabilidad. Sobre esto, la Corte IDH ha sostenido que «la capacidad de diferenciación de las autoridades con base en esos criterios sospechosos se encuentra limitada, y solo en casos en donde las autoridades demuestren que se está en presencia de necesidades imperiosas, y que recurrir a esa diferenciación es el único método para alcanzar esa necesidad imperiosa, podría eventualmente admitirse el uso de esa categoría ${ }^{45}$.

Actualmente, estas consideraciones podrían ser decisivas para América Latina, dado el estado de cosas que ha sido generado por la pandemia de COVID-19. Los numerosos informes de CEPAL (2020a; 2020b; 2020c; 2020d) sugieren un panorama actual y futuro en el que la aporofobia no debe pasar inadvertida por los Estados. De hecho, desde que la pandemia desplegó sus efectos en la región y se proliferó la adopción de medidas estatales de toda clase - prohibiciones de ingreso al país por parte de nacionales, cuarentenas domiciliares, conducción a centros de contención por incumplir las cuarentenas, etc.- - la $\mathrm{CIDH}$ ya se anticipaba a las posibles discriminaciones basadas en la pobreza. En la resolución n. ${ }^{\circ} 1 / 2020$ «Pandemia y derechos humanos en las Américas", instó a los Estados a "prestar especial atención a las necesidades y al impacto diferenciado de las medidas en los derechos humanos de los grupos históricamente excluidos o en especial riesgo, tales como: [...] personas que viven en pobreza y pobreza extrema» $(\mathrm{CIDH}, 2020: 7)^{46}$.

44 Corte IDH. Sentencia de 1 de septiembre de 2015 (excepciones preliminares, fondo, reparaciones y costas), Caso Gonzáles Lluy vs. Ecuador, párrafo 257.

45 Ibid., párrafo 256.

46 Curiosamente, la Agenda 2030 de la Organización de las Naciones Unidas (2015: 4) ya aludía al ideal universal de un mundo «sin pobreza, hambre, enfermedades ni privaciones». Lo curioso es que la COVID-19 trajo consigo una paradoja ética: aunque los valores reflejados por los mandatarios de los países del mundo en dicha agenda sugerían el combate de la pobreza y la enfermedad, cuando la enfermedad llegó se tomaron decisiones que afectaron más a los pobres que al resto: imposibilidad de comercio informal, escuelas públicas cerradas en contextos de brecha digital, etc. 
La afirmación que antecede se puede ejemplificar. Primero, considerando que dos de las grandes medidas para prevenir la COVID-19 son el lavado de manos y quedarse en casa, al punto en que la Organización Panamericana de la Salud y la Organización Mundial de la Salud ofrecieron cursos sobre el primer tema (2021: 3). Pero resulta que ambas son imposibles de cumplir en el contexto de profundas desigualdades sociales y económicas de Latinoamérica, en vista de las serias dificultades para acceder al agua limpia y de las condiciones de hacinamiento de cinco a diez personas en la misma habitación en que muchos viven. Como escriben Gargarella y Roa Roa, «bajo estas circunstancias, quizás el mejor consejo médico hubiera sido justo lo opuesto al ofrecido entonces, tal vez uno como este: "sal de tu lugar y toma un poco de aire fresco en un parque"» (2020: 13).

Segundo, atendiendo a que una de las medidas predilectas en América Latina fue la cuarentena, resguardo o aislamiento domiciliar obligatorio $(\mathrm{CIDH}$, 2020: 4), debió considerarse que la población en condición de pobreza por lo general se dedica al comercio informal o a empleos formales sensiblemente afectados por ellas — industria hotelera, restaurantes o construcción-(CEPAL, 2020d: 13). Dado que esta afectación no podía aliviarse con salidas alternativas como el teletrabajo (Weller, 2020: 13), los Estados que adoptaron confinamientos exageradamente duraderos e inflexibles colocaron a las personas pobres en una situación todavía más comprometida y delicada de lo usual ${ }^{47}$.

Lamentablemente, todo esto no sorprende, pues como explica J. Butler (2020: 62):

La desigualdad social y económica asegurará que el virus discrimine. El virus por sí solo no discrimina, pero los humanos seguramente lo hacemos, modelados como estamos por los poderes entrelazados del nacionalismo, el racismo, la xenofobia y el capitalismo. Es probable que en el próximo año seamos testigos de un escenario doloroso en el que algunas criaturas humanas afirmarán su derecho a vivir a expensas de otros, volviendo a inscribir la distinción espuria entre vidas dolorosas e ingratas, es decir, aquellos quienes a toda costa serán protegidos de la muerte y esas vidas que se considera que no vale la pena que sean protegidas de la enfermedad y la muerte.

Esto invita a que la Corte IDH y los tribunales de la región examinen todas las medidas relacionadas con la COVID-19 tomando como punto de partida que la condición de pobreza es una categoría sospechosa de discriminación y que toda acción u omisión aporofóbicas se presumen inconvencionales e

47 Tómese como ejemplo a Argentina. Según consta en notas periodísticas (una de ellas es la de BBC, https://bbc.in/2RhnKE8), en tal país la cuarentena se prolongó por más de cinco meses y tuvo un carácter sumamente inflexible. 
inconstitucionales, de manera que es el Estado quien debe justificar su necesidad imperiosa. Ahora bien, en virtud de que muchos tribunales constitucionales latinoamericanos han ido adoptando crecientemente ciertas prácticas de justicia dialógica —acción pública de constitucionalidad, amicus curiae, litigios estructurales o audiencia públicas-, a pesar de la más que evidente lógica agonal que inspira a nuestro constitucionalismo (Gargarella, 2014b: 119-123), resulta necesario poseer insumos teóricos para que en su proceder la voz de los pobres cuente como una opinión importante. Y es que hay un fundamento democrático elemental en que las personas en condición de pobreza puedan hacerse oír por las instituciones públicas: si es un grupo numeroso, hay un interés mayoritario en que las medidas estatales les tomen en cuenta (Little, 2003: 243).

Sobre este tema, resulta interesante la propuesta de Carlos Bernal respecto del análisis dialógico de proporcionalidad para aplicar los derechos sociales - entre ellos estarían la salud y educación, ampliamente afectados en el contexto de la pandemia-. Bernal propone que también los destinatarios o titulares de tales derechos puedan tener voz en cuanto al nivel y modo apropiados de satisfacerlos (Bernal Pulido, 2018: 157-158):

Aquí se propone un análisis dialógico de proporcionalidad para aplicar los derechos sociales positivos. A diferencia de lo que ocurre con las libertades constitucionales, aplicar los derechos sociales positivos no puede ser en exclusiva una tarea de los jueces. Los titulares y los destinatarios son quienes están en mejor posición para argumentar, por medio de premisas normativas y empíricas, cuál debe ser el nivel y el modo apropiado para satisfacer estos derechos. La labor de los jueces es controlar la plausibilidad de dichas premisas y tales argumentos. Además, la participación de los destinatarios en este diálogo refuerza su compromiso con la satisfacción de los derechos sociales. Así, el diálogo provee una base argumentativa para la toma de decisiones judiciales y para el diseño y la ejecución de las políticas necesarias para cumplirlas.

\section{CONCLUSIONES}

La pobreza posee más de un concepto posible. Todos ellos parecieran vincularse en mayor o menor medida con los ingresos que una persona percibe, ya bien como un elemento autónomo o en conjunción con otros. Además, el criterio económico para la medición de la pobreza sigue siendo el más conocido y usado: en América Latina es utilizado por Argentina, Brasil, Colombia, El Salvador, Guatemala, Honduras, Jamaica, Panamá, Paraguay, Surinam y Uruguay. Con base en él, debe trazarse una línea de pobreza a partir de los ingresos, y si no se supera dicha línea, entonces se está dentro de tal condición. Desafortunadamente, más del $30 \%$ de los latinoamericanos son pobres y se 
prevé que este porcentaje se eleve a raíz de la pandemia por la COVID-19, la cual, dicho sea de paso, ha visibilizado las brechas que existen entre las personas en condición de pobreza respecto de quienes no están en ella.

Es tal la magnitud y recurrencia de la discriminación hacia los pobres que se ha acuñado un concepto que designa a esta realidad: aporofobia. La pobreza se considera una categoría sospechosa de discriminación a la luz de la $\mathrm{CADH}$, cuyo artículo 1.1 prevé el deber de respetar y garantizar los derechos humanos de todas las personas, sin discriminación por su posición económica. Y dado que todos los conceptos de pobreza analizados se pueden vincular con los ingresos y el criterio económico para su medición sigue siendo el más conocido y usado, es razonable sostener que esta cláusula le es aplicable. Esto podría respaldarse en doctrina, estudios, opiniones y precedentes de la Comisión y Corte IDH. En todo caso, aunque no se aplicase esta norma directamente estatuida, por la larga historia de discriminación y exclusión sufrida por los pobres, siempre cabría considerarla como una de esas categorías si se parte del concepto de desigualdades estructurales y del carácter abierto e ilustrativo que tiene el art. 1.1 CADH. Todo lo dicho lleva a afirmar que la aporofobia está proscrita en todos los países suscriptores de la $\mathrm{CADH}$.

Además, el principio de igualdad, reconocido por las constituciones de los países de la región, es una norma regulativa que fundamenta la prohibición de discriminación desde el derecho interno. Algunas de estas constituciones, como la de Bolivia, Ecuador, México, Perú y Venezuela, admiten, desde su texto, la adscripción de la norma prohibitiva de la aporofobia y la consideración de la pobreza como categoría sospechosa de discriminación. En otras, como la de Colombia, Costa Rica, Honduras y El Salvador, esta adscripción y consideración puede hacerse con base en tres argumentos: a) las constituciones no deben interpretarse de forma textual; b) muchos tribunales constitucionales de países en los que las constituciones prevén otras categorías sospechosas, pero no la pobreza, reconocen que se trata de listados no taxativos; y c) las constituciones se deben interpretar evolutivamente para mantener su legitimidad democrático-sustancial, y los derechos de los más débiles se identifican con esta: según los datos, en Latinoamérica las personas pobres están en ese grupo en desventaja.

Finalmente, las consecuencias inmediatas de que la pobreza se considere como una categoría sospechosa de discriminación son las que siguen: en primer lugar, se presume la inconvencionalidad e inconstitucionalidad de toda medida discriminatoria en la que este criterio intervenga, a la vez que se invierte la carga de la prueba, lo que significa que en presencia de dichas medidas corresponde a la autoridad que las adoptó demostrar que su decisión no tenía un propósito ni un efecto discriminatorio. En segundo lugar, el Estado únicamente podría justificar la discriminación realizada si aduce un fin 
constitucional o convencional imperativo que sustente su aceptabilidad. Estas y otras consideraciones efectuadas en este artículo podrían ser decisivas para América Latina al enjuiciar las acciones u omisiones estatales que se adopten por la pandemia de COVID-19.

\section{Bibliografía}

Ackerman, B. (2011). La constitución viviente. Madrid: Marcial Pons.

Aguiló Regla, J. (2012). Interpretación constitucional. Algunas alternativas teóricas y una propuesta. DOXA, Cuadernos de Filosofia delDerecho, 35, 235-258. Disponible en: https://doi.org/10.14198/DOXA2012.35.11.

Ahmed, M. y Bredenkamp, H. (2000). Apoyo a la reducción de la pobreza en los países en desarrollo de bajo ingreso. Finanzas y Desarrollo, 10-13. Disponible en: https://bit.ly/2RhiAbe.

Alexy, R. (2012). Teoría de los derechos fundamentales. Madrid: Centro de Estudios Políticos y Constitucionales.

Andersson, M. y Axelsson, T. (2016). Diversity of development paths and structural transformation in historical perspective. En M. Andersson y T. Axelsson (eds.). Diverse development paths and structural transformation in the escape from poverty. Oxford: Oxford University Press. Disponible en: https://doi.org/10.1093/ acprof:oso/9780198737407.001.0001.

Angel, R. J. (2016). Social class, poverty, and the unequal burden of illness and death. En D. Brady y L. M. Burton (eds.). The Oxford handbook of the social science of poverty (pp. 660-683). Oxford: Oxford University Press. Disponible en: https:// doi.org/10.1093/oxfordhb/9780199914050.013.30.

Añón, M. J. (2008). Igualdad, diferencias y desigualdades. México: Fontamara.

Atienza, M. (2013). El sentido del derecho. Barcelona: Ariel.

Atienza, M. y Ruiz Manero, J. (2016). Las piezas del derecho. Teoría de los enunciados juridicos. Barcelona: Ariel.

Baldassarre, A. (2004). Los derechos sociales. Bogotá: Universidad Externado de Colombia.

Barak, A. (2017). Proporcionalidad. Los derechos fundamentales y sus restricciones. Lima: Palestra.

Beck, V., Hahn, H. y Lepenies, R. (2020). Interdisciplinary perspectives on poverty measurement, epistemic injustices and social activism. En V. Beck, H. Hahn y R. Lepenies (eds.). Dimensions of poverty (pp. 1-20). Cham, Suiza: Springer. Disponible en: https://doi.org/10.1007/978-3-030-31711-9_1.

Bernal Pulido, C. (2008). Elderecho de los derechos. Bogotá: Universidad Externado de Colombia.

Bernal Pulido, C. (2014). El principio de proporcionalidad. Bogotá: Universidad Externado de Colombia. 
Bernal Pulido, C. (2018). Derechos, cambio constitucional y teoría jurídica. Escritos de Derecho Constitucional y teoría del derecho. Bogotá: Universidad Externado de Colombia. Disponible en: https://doi.org/10.2307/j.ctv1ddcv87.

Bilbao Ubillos, J. M. y Rey Martínez, F. (2003). El principio constitucional de igualdad en la jurisprudencia española. En M. Carbonell (comp.). El principio constitucional de igualdad. Lecturas de introducción. México: Comisión Nacional de los Derechos Humanos.

Bilchitz, D. (2017). Pobreza y derechos fundamentales. La justificación y efectivización de los derechos socioeconómicos. Madrid: Marcial Pons.

Bobbio, N. (1993). Igualdad y libertad. Barcelona: Ediciones Paidós.

Butler, J. (2020). El capitalismo tiene sus límites. En G. Agamben, S. ŽiŽek y otros. Sopa de Wuhan (pp. 59-65). Argentina: Aislamiento Social, Preventivo y Obligatorio.

CEPAL (2019). Panorama social de América Latina, 2019. Santiago. Disponible en: https://bit.ly/3eNJYFN.

CEPAL (2020a). América Latina y el Caribe ante la pandemia del COVID-19. Efectos económicos y sociales. Disponible en: https://bit.ly/2PLWa1u.

CEPAL (2020b). Universalizar el acceso a las tecnologías digitales para enfrentar los efectos del COVID-19. Disponible en: https://bit.ly/2RlllIs.

CEPAL (2020c). La educación en tiempos de la pandemia de COVID-19. Disponible en: https://bit.ly/3tdiZZI.

CEPAL (2020d). Informe sobre el impacto económico en América Latina y el Caribe de la enfermedad por coronavirus (COVID-19). Santiago. Disponible en: https:// bit.ly/3xGWxeS.

$\mathrm{CIDH}$ (2017). Informe sobre pobreza y derechos humanos en las Américas. Disponible en: https://bit.ly/2RIPN5u.

CIDH (2019). Compendio sobre la igualdad y no discriminación. Estándares interamericanos. Disponible en: https://bit.ly/3tmQ0Tn.

CIDH (2020). Resolución $n .^{\circ}$ 1/2020. Pandemia y derechos humanos en las Américas. Disponible en: https://bit.ly/2ReCSlH.

CIDH (2013). Homero Flor Freire. Informe n. ${ }^{\circ}$ 81/13, caso 12743 , fondo. Ecuador, 4 de noviembre de 2013. Disponible en: https://bit.ly/3ukyv7u.

Cortina, A. (1997). El mundo de los valores. Ética y educación. Santafé de Bogotá: Editorial El Búho.

Cortina, A. (2017). Aporofobia, el rechazo al pobre. Un desafío para la democracia. Barcelona: Paidós.

Díaz de Valdés, J. M. (2015). La igualdad constitucional: múltiple y compleja. Revista Chilena de Derecho, 42, 1, 153-187. Disponible en: https://doi.org/10.4067/ S0718-34372015000100007.

Díaz Revorio, F. J. (2016). Interpretación de la Constitución y juez constitucional. Revista del Instituto de Ciencias Jurídicas de Puebla, 27, 9-31. Disponible en: https://bit.ly/2RllZpm.

Escobar Roca, G. (2018). Nuevos derechos y garantías de los derechos. Madrid: Marcial Pons. 
Ferrajoli, L. (2004). Derechos y garantías. La ley del más débil. Madrid: Trotta.

Ferrer Mac-Gregor, E. (2013). Panorámica del Derecho Procesal Constitucional y Convencional. España: Marcial Pons.

Ferrer Mac-Gregor, E. (2014). Control de convencionalidad (sede interna). En E. Ferrer Mac-Gregor, F. Martínez Ramírez y G. Figueroa Mejía (coords.). Diccionario de Derecho Procesal Constitucional y Convencional (pp. 233-236). México: Poder Judicial de la Federación.

Fix-Zamudio, H. (2013). Relaciones entre los tribunales constitucionales latinoamericanos y la Corte Interamericana deDerechos Humanos. En E. Ferrer Mac-Gregor y A. Herrera García (coords.). Diálogo jurisprudencial en derechos humanos entre tribunales constitucionales y cortes internacionales. México: Tirant lo Blanch.

Fredman, S. (2020). Poverty and human rights: a peril and a promise. En D. Akande, J. Kuosmanen, H. McDermott y D. Roser (eds.). Human rights and 21st century challenges: poverty, conflict, and the environment. Oxford: Oxford University Press. Disponible en: https://doi.org/10.1093/oso/9780198824770.003.0011. Gargarella, R. (2014a). La sala de máquinas de la Constitución. Dos siglos de constitucionalismo en América Latina (1810-2010). Argentina: Katz. Disponible en: https://doi.org/10.2307/j.ctvm7bcjw.

Gargarella, R. (2014b). El nuevo constitucionalismo dialógico frente al sistema de los frenos y contrapesos. En R. Gargarella (comp.). Por una justicia dialógica. El poder judicial como promotor de la deliberación democrática. Argentina: Siglo Veintiuno.

Gargarella, R. y Roa Roa, J. E. (2020). Diálogo democrático y emergencia en América Latina. Max Planck Institute for Comparative Public Law and International Law. Disponible en: http://dx.doi.org/10.2139/ssrn.3623812.

Giménez Glück, D. (2004). Juicio de igualdad y Tribunal Constitucional. Barcelona: Bosch.

Greve, B. (2020). Poverty: The basics. New York: Routledge. Disponible en: https:// doi.org/10.4324/9780429297007.

Häberle, P. (2019). Los derechos fundamentales en el Estado prestacional. Lima: Palestra. Haugen, G. A. y Boutros, V. (2014). The locust effect. Why the end of poverty requires the end of violence. Oxford: Oxford University Press.

Hierro, L. L. (2009). Estado de derecho. Problemas actuales. México: Fontamara. Iceland, J. (2003). Poverty in America. California: University of California Press.

Keren-Paz, T. (2016). Derecho de daños, igualdad y justicia distributiva. Madrid: Marcial Pons.

Lang, K. (2007). Poverty and discrimination. Princeton: Princeton University Press. Disponible en: https://doi.org/10.1515/9781400839193.

Little, D. (2003). The paradox of wealth and poverty: Mapping the ethical dilemmas of global development. Boulder, Colorado: Westview Press.

Malem Seña, J. F. (2017). Pobreza, corrupción, (in)seguridad jurídica. Madrid: Marcial Pons. Disponible en: https://doi.org/10.2307/j.ctv10qr07r. 
Montealegre Lynett, E., Bautista Pizarro, N., y Vergara Peña, L. F. (2014). La actualidad del principio de proporcionalidad y de la ponderación en Alemania. En E. Montealegre Lynett, N. Bautista Pizarro y L. F. Vergara Peña (comps.). La ponderación en el derecho. Bogotá: Universidad Externado de Colombia.

Nino, C. S. (1995). Un pais al margen de la ley. Estudio de la anomia como componente del subdesarrollo argentino. Buenos Aires: Emece.

Organización de las Naciones Unidas (2015). Transformar nuestro mundo: la Agenda 2030 para el Desarrollo Sostenible. Resolución de 18 de septiembre. Disponible en: https://bit.ly/3edfjTh.

Organización Mundial de la Salud (2014). Estadisticas sanitarias mundiales 2014. Una mina de información sobre salud pública mundial. Disponible en: https:// bit.ly/3xIJDgj.

Organización Panamericana de la Salud y Organización Mundial de la Salud (2021). Respuesta de la OPS/OMS. Informe n. ${ }^{\circ} 40$. Disponible en: https://iris.paho.org/ handle/10665.2/53235.

Pisarello, G. (2007). Los derechos sociales y sus garantías. Madrid: Trotta.

Ramírez Cleves, G. (2009). Pobreza, globalización y derecho. Bogotá: Universidad Externado de Colombia.

Rubio Llorente, F. (1989). El bloque de constitucionalidad. Revista Española de Derecho Constitucional, 27, 9-37. Disponible en: https://bit.ly/3nFgzlo.

Ruiz Miguel, A. (1996). La igualdad en la jurisprudencia del Tribunal Constitucional. DOXA, Cuadernos de Filosofía del Derecho, 19, 39-86. Disponible en: https://doi.org/10.14198/DOXA1996.19.03.

Saba, R. (2005). (Des)igualdad estructural. Revista Derecho y Humanidades, 11, 123-147. Disponible en: https://bit.ly/3uduNfO.

Sarlet, I. W. (2019). La eficacia de los derechos fundamentales. Una teoría general desde la perspectiva constitucional. Lima: Palestra.

Schweiger, G. y Graf, G. (2015). A philosophical examination of social justice and child poverty. New York: Palgrave Macmillan. Disponible en: https://doi. org/10.26530/OAPEN_579612.

Smeeding, T. M. (2016). Poverty measurement. En D. Brady y L. M. Burton (eds.). The Oxford handbook of the social science of poverty. Oxford: Oxford University Press. Disponible en: https://doi.org/10.1093/oxfordhb/9780199914050.013.3.

Solozabal Echavarria, J. J. (2013). La garantía de la igualdad. En J. L. García Guerrero (dir.). Los derechos fundamentales. La vida, la igualdad y los derechos de libertad (pp. 75-92). Valencia: Tirant lo Blanch.

Treacy, G. F. (2011). Categorías sospechosas y control de constitucionalidad. Lecciones y Ensayos, 89, 181-216. Disponible en: https://bit.ly/2QHX1Rq.

United Nations Development Programme (PNUD) (2020). Temporary basic income: Protecting poor and vulnerable. Disponible en: https://bit.ly/2PJHq33.

Vela Ávalos, M. A. (2021). El debate sobre la especificidad de la interpretación de la Constitución en el contexto latinoamericano. Una discusión desde cuatro trincheras. Revista de Derecho Público: Teoría y Método, 3, 53-84. Disponible en: https://doi.org/10.37417/RPD/vol_1_2021_527. 
Vilajosana, J. M. (2010). El derecho en acción. La dimensión social de las normas jurídicas. Madrid: Marcial Pons.

Weller, J. (2020). La pandemia del COVID-19 y su efecto en las tendencias de los mercados laborales. Santiago de Chile: CEPAL.

\section{Jurisprudencia}

Corte Constitucional de Colombia, Sentencia de 11 de febrero de 2019, T-050/19.

Corte Constitucional de Colombia, Sentencia de 13 de octubre de 2010, C-818/10.

Corte Constitucional de Colombia, Sentencia de 13 de septiembre de 2017, C-571/17.

Corte Constitucional de Colombia, Sentencia de 22 de febrero de 2017, C-115/17.

Corte Constitucional de Colombia, Sentencia de 26 de octubre de 2016, C-586/16.

Corte Constitucional de Ecuador, Sentencia de 7 de septiembre de 2016, n. ${ }^{\circ} 292-16$ SEP-CC.

Corte IDH. Condición jurídica y derechos de los migrantes indocumentados. Opinión Consultiva OC-18/03, de 17 de septiembre de 2003.

Corte IDH. Sentencia de 1 de septiembre de 2015 (excepciones preliminares, fondo, reparaciones y costas), caso Gonzáles Lluy vs. Ecuador.

Corte IDH. Sentencia de 26 de septiembre de 2006 (excepciones preliminares, fondo, reparaciones y costas), caso Almonacid Arellano y otros vs. Chile.

Corte IDH. Sentencia de 9 de marzo de 2018 (fondo, reparaciones y costas), caso Ramírez Escobar y otros vs. Guatemala.

Sala de lo Constitucional de El Salvador, Sentencia de 10 de agosto de 2015, inconstitucionalidad 112-2012.

Sala de lo Constitucional de El Salvador, Sentencia de 19 de agosto de 2020, controversia 8-2020.

Sala de lo Constitucional de El Salvador, Sentencia de 23 de diciembre de 2016, inconstitucionalidad 156-2012.

Sala de lo Constitucional de El Salvador, Sentencia de 23 de octubre de 2020, inconstitucionalidad 98-2015.

Sala de lo Constitucional de El Salvador, Sentencia de 28 de mayo de 2018, inconstitucionalidad 146-2014/107-2017.

Sala de lo Constitucional de El Salvador, Sentencia de 8 de junio de 2020, inconstitucionalidad 21-2020 AC.

Sala de lo Constitucional de El Salvador, Sentencia de 9 de diciembre de 2009, amparo 18-2004.

Sala de lo Constitucional de El Salvador, Sentencia de 9 de octubre de 2017, inconstitucionalidad 44-2015/103-2016.

Tribunal Constitucional de Perú, Sentencia de 14 de octubre de 2009, exp. n. ${ }^{\circ}$ 01604-2009-PA/TC.

Tribunal Constitucional de Perú, Sentencia de 3 de septiembre de 2010, exp. n. ${ }^{\circ}$ 2317-2010-AA/TC. 